\title{
Semi Autonomous LHD operational philosophy for panel caving applications
}

\author{
H Vega CODELCO, Chile \\ R Castro University of Chile, Chile
}

\begin{abstract}
In recent years, there has been an increase in the number of caving operations using or planning to use autonomous LHDs to extract ore from drawpoints. There are several reasons for adopting this type of technology including health, safety, and productivity improvements. Currently operating caving mines that have adopted autonomous LHD use the Block Caving method, where development has been completed prior to initiating production activities. Panel Caving is a method in which development and production activities have to be conducted simultaneously in a production drive. In this article, a Semi Autonomous LHD Operational Philosophy (SLOP) for the use of autonomous LHDs in a panel caving operation is proposed. The SLOP considers aspects such as the technology requirements, the material handling design, and the production plan to achieve successful implementation of this technology in panel caving operations. Finally, a case study on applying SLOP in the Andesita Mine at El Teniente is presented.
\end{abstract}

\section{Introduction}

Automation is one of the most important keys in underground mines to improve safety and productivity. In terms of safety, automation eliminates the operator's exposure to any uncontrolled or risky situation in an underground environment (Uribe 2014). Teleremote operations from a Control Room located on the surface have been used worldwide, implemented in operations such as Freeport Indonesia (DOZ, GBC and DMLZ), LKAB (Kiruna), Northparkes and CODELCO (Andina and El Teniente). Through automation, these mines have not only ensured the safety of operators but also improved their quality of life.

The main scope of automation has been to apply it to activities that are complex and/or repetitive. Implementing this technology has resulted in higher productivity and effective operating time and as a result lower operating costs. An example of repetitive activities are train automated operations implemented in GBC, Kiruna and El Teniente, where the dispatch system controls train speed, point machines, safety distances, optimized tramming routes, among others (Shekhar 2017).

In terms of underground production equipment, LHDs (Load Haul Dump) are very common in both Block and Panel Caving mines. Semi autonomous LHDs have been implemented and operated since 2004 in Pipa Norte and Diablo Regimiento mines (El Teniente) with good results through the life of those mines (Codelco 2007). Northparkes is another example of successful Semi autonomous LHD implementation (Vega 2020). However, it is worth noting that in these cases the automation was implemented in a Block Caving mine scenario, which means the panels were already fully developed and constructed before the commencement of automation to avoid any human-LHD interaction.

Panel Caving mines are different as construction coexists with production, and this interaction in most cases is unavoidable. Therefore, the challenge is to define an area with minimum infrastructure requirements to start with the automation in Panel Caving mines, taking into account that construction 
and production activities coexist in the same panel or vicinity. This area is called the Initial Production Module (IPM) and will be the focus of this study. In addition to the IPM, the automation technical and layout criteria will be part of the analysis (Vega 2020).

\section{Technical criteria in automation design}

The automation design for the IPM needs to include the following topics (Gustafson 2013; Riquelme 2014; JRI 2019a; JRI 2019b; BCTEC 2019):

- Local and international standards and regulations. It is important for the traceability of the implementation of the system.

- Control Room. This centralized Control Room must be able to gather information to control and dispatch the equipment. It is usually located on the surface where the quality of life is better. In addition, most mines have a secondary Control Room underground close to the production area that is used for emergency cases, commissioning periods or maintenance purposes.

- Control systems. These systems support production and the equipment and are composed of many devices that control, manage and guide the semi autonomous equipment. These systems are put in place to achieve the production goals in terms of tons, but also to minimize corrective maintenance and improve the operational safety.

- Production management system. Production scheduling in Panel Caving mines is key to have normal caving conditions and to avoid geotechnical issues, early dilution, or cave back singularity. Semi autonomous LHDs provide the opportunity to fully follow the caving and production rules and allow a new operating philosophy to be implemented.

- Confinement system. Isolating the semi autonomous LHDs avoids any interaction with people or other equipment that may cause a potential accident; physical or logical control gates are needed to achieve this. Physical control gates prevent the access of people or other equipment into the isolated area and are operated from the Control Room. Logical control gates control interaction amongst semi autonomous equipment within the isolated area.

- WiFi network. This connects all the underground mobile and fixed equipment with the control room for communication between the on board LHD system and the Access Points (wireless network device). It receives and sends data to the Control Room in real time.

- On Board systems. These systems read the status of the LHD and send the information to the Control Room. As well, on board systems receive information from the Control Room and follow instructions. On board systems let the LHD have semi autonomous operation (no operator is needed) and have devices that control navigation, wireless communication, maintenance indicators, audio and video, among others.

- Register zones. LHDs operate semi autonomously in an isolated production area and on manual with an operator on board when out of the isolated production area. For the transition or interface between these two areas, the register zones are needed. They are usually located close to the production area and physical gates and help to isolate the change of operational methodology.

Figure 1 shows how the automation systems are connected from the Control Room (that could be on the surface or underground) to the LHD in operation through a communication network. 


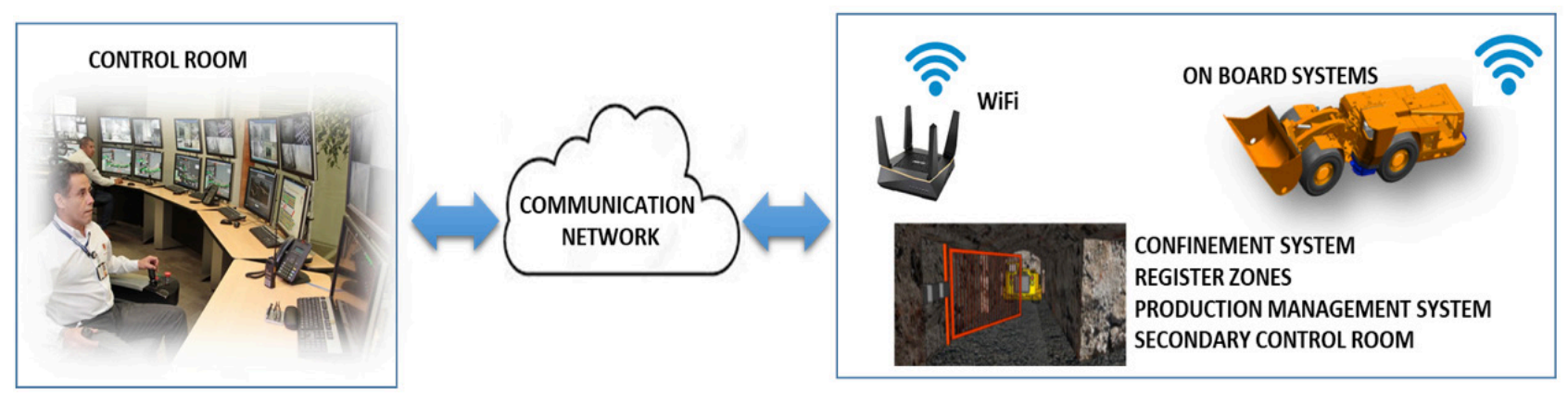

Figure 1 Automation Control System configuration

\section{$3 \quad$ Layout criteria in the automation design}

The IPM configuration that incorporates geotechnical recommendations must meet some criteria to avoid any issue in the future with automation. The main topics to be considered are the following (Vega 2020; BCTEC 2019):

- Panel clearance. The panel design must be wide enough to avoid any sensor triggered by proximity or collision with the walls, which will make the LHD stop for safety reasons or, in the worst case, will damage the equipment. A minimum of $0.5 \mathrm{~m}$ clearance must be maintained from the suspended services such as water, compressed air, power. Closer proximity to these services may give a false collision alarm.

At the same time, for a good and simple confinement design, interference with any external task by the production of semi autonomous LHDs must be minimized. For instance, geological or geotech field inspection may stop only the semi autonomous LHD (if any) located in the panel to be checked rather than having to stop the whole Extraction Level.

Finally, keeping the panels clean along the way of the semi autonomous LHD is key to avoid any collision of the chassis or axles with the spillage coming from drawpoints.

- Operational interferences. There are many sources of interference that the design must take into account to minimize their impact on LHD productivity. Some of these are secondary blasting, geological or geotech field inspections, infrastructure maintenance, refuelling, among others.

- Construction requirements. These are some of the requirements that the IPM needs to support the automation:

Mining and construction: All areas where the semi autonomous LHD will operate must be complete in terms of ground support and construction (panels, drawpoints, walls, roadway, ventilation, etc.)

Mineral handling: The complete mineral handling system in regards to the drawpoints available must be finished (dumping points, grizzlies, rock breakers, etc.)

$\square$ Drawpoints available: The number of drawpoints needed for the IPM in a panel varies depending on the drawbell opening sequence and the location of the dumping point. If the sequence goes towards the dumping point, then automation cannot be implemented in the panel until the sequence passes through the dumping point. If construction activities are still in progress between the last drawpoint in production and the dumping point, this area cannot be fully isolated for automation purposes. Interaction between automated loaders and people or other machines cannot coexist.

On the other hand, if the sequence goes away from the dumping point, then automation can be implemented in a panel starting from one or two drawbells. This is possible because 
the area between the last drawpoint in production and the dumping point can be isolated for automation purposes. The construction activities would be able to occur outside of this isolated area.

Figure 2 shows the idea of this sequence explanation and the dumping point location.
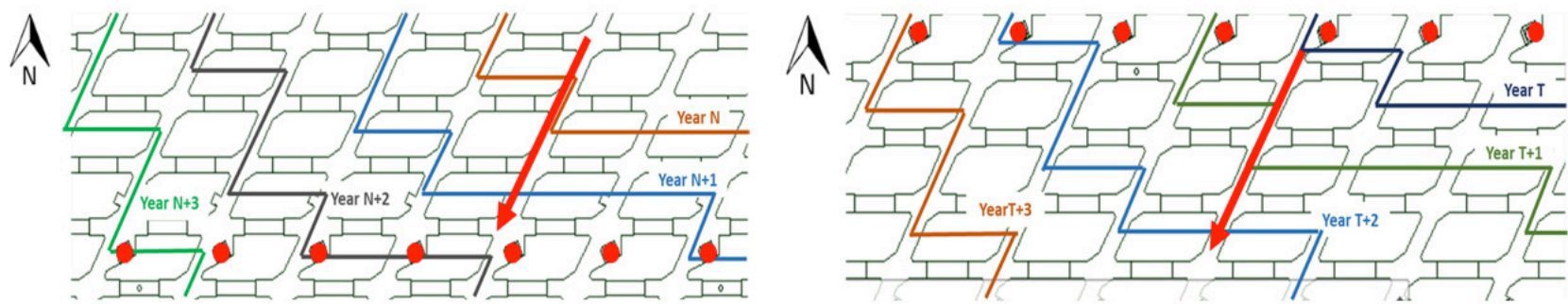

Figure 2 Drawbell opening sequence and dumping point location: The figure on the left shows a sequence that cannot be automated until construction is completed. The figure on the right shows a sequence that permits operations while construction is taking place

In both cases the following need to be considered:

u Services: All the supplies have to be installed and operating before automation starts (water, compressed air, energy).

u Semi autonomous system: All the technical criteria and devices described above have to be installed previously

- Operational rules: In order to coordinate and manage the LHD fleet, operational rules must be followed. The rules vary from mine to mine or by design, but in general they are focused on LHD assignments, draw control, coordination between different activities, etc.

\section{$4 \quad$ Initial production module (IPM) philosophy}

All the inputs previously described in terms of technical and layout criteria depend on each mine configuration, but the minimum required for the IPM are summarized in Table 1 (Vega 2020; BCTEC 2019).

Table 1 Minimum requirements for the IPM

\begin{tabular}{|c|c|}
\hline Design & Criteria \\
\hline Mining and construction & $\begin{array}{c}\text { Tunnels and infrastructure (walls, drawpoints, roadway, } \\
\text { etc.) where the semi autonomous LHD operates have to be } \\
\text { completely finished with permanent ground support. } \\
\text { Minimum one (1) but will depend on the strategy of each } \\
\text { project/mine in terms of drawpoint opening sequence, } \\
\text { safety distances and the dumping point location. }\end{array}$ \\
\hline Mineral handling system & Minimum one (1) finished and ready for operation. \\
\hline Services & Completely installed. \\
\hline Automation system & $\begin{array}{r}\text { Finished in the confinement area (field devices, gates, on } \\
\text { board systems) and Control Room. }\end{array}$ \\
\hline
\end{tabular}

\section{$5 \quad$ An automation design: Andesita Project}

The Andesita Project is currently one of the most important projects for El Teniente Division (CODELCO) and will start production at the end of 2023. It will use Conventional Panel Caving with hydraulic 
preconditioning and a peak of production of $25 \mathrm{ktpd}$ with 18 years of life of mine. The footprint area will be roughly 250,000 $\mathrm{m}^{2}$ (JRI 2019c; JRI 2019e).

The mineral handling configuration will have semi autonomous LHDs in the Extraction Level dumping into one out of nine ore bins located outside the footprint. The main Haulage Level with trains, located $30 \mathrm{~m}$ below, will take the production out to the plant (JRI 2019e).

Figure 3 shows the Extraction Level configuration, and the 23 panels this project will have (Codelco 2018).

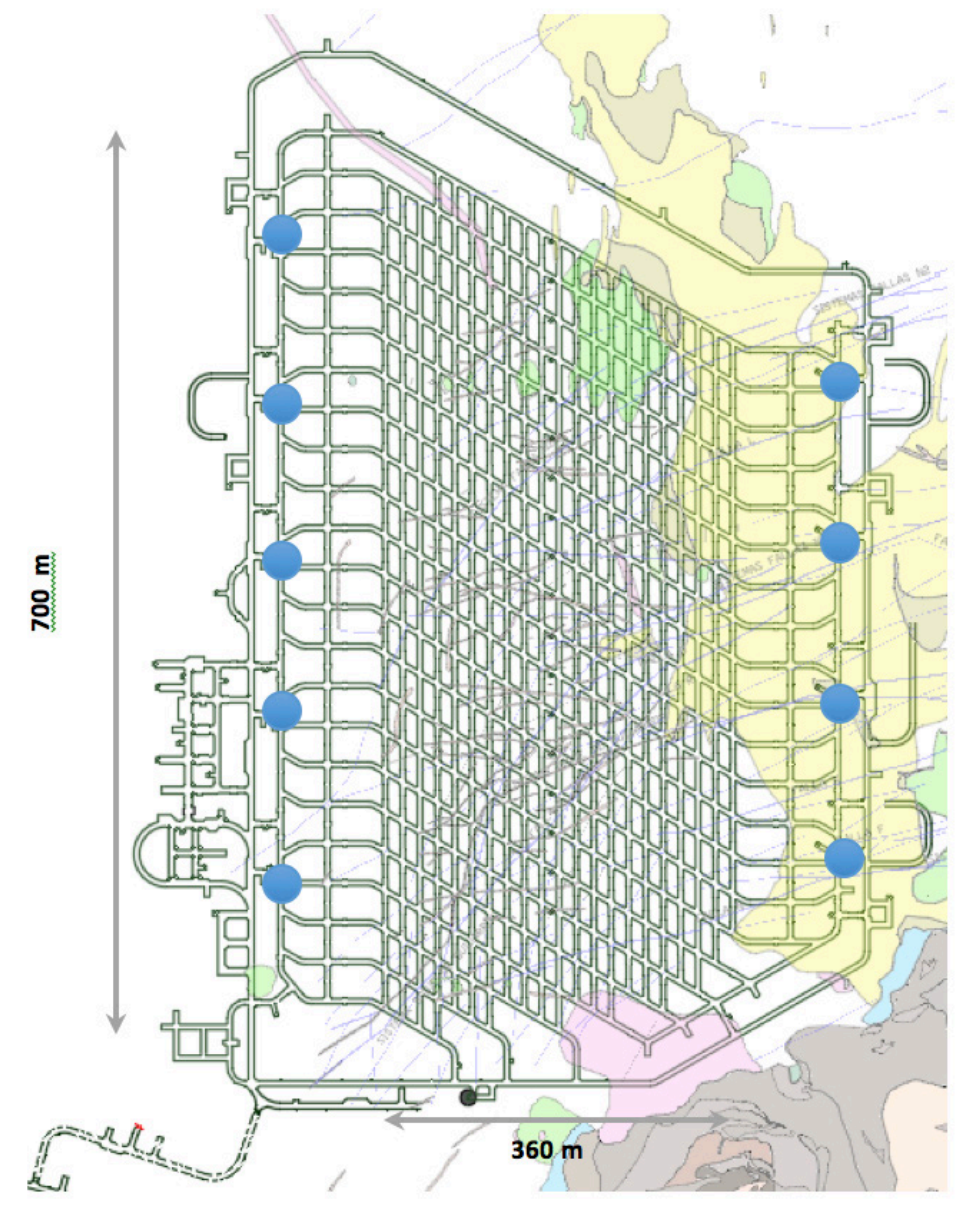

Figure 3 Extraction Level of Andesita Project and the location of the dumping points

Dumping points will be ore bins located out of the footprint area with an opening of $7 \times 7 \mathrm{~m}$, a grizzly of $1 \times 1 \mathrm{~m}$ configuration and a rock breaker for oversize. Each dumping point will have three accesses and the capacity for three LHDs to dump at the same time (JRI 2018a; JRI 2018b; JRI 2019e).

\subsection{Technical criteria}

LHDs will be semi autonomous, and loading from drawpoints will be teleremote-operated from the Control Room located in the town of Rancagua, which is $50 \mathrm{~km}$ away. The operator will be able to handle up to 3 LHDs because of haulage distances (average of $170 \mathrm{~m}$ roughly, one way).

At the same time, the project will have a secondary Control Room located in its fixed facilities in the Extraction Level for equipment and system commissioning, maintenance or backup for emergency cases. This secondary Control Room will have 30\% of the main Control Room capacity (JRI 2018b; JRI 2019a).

Even though the Andesita Project will include all the items described in Technical criteria in automation Design described in Section 2 above, two important topics must be highlighted: 
- Confinement system

The Project will install physical and logical gates that completely isolate the areas where the LHDs will operate and avoid any interaction with other operations or people. Figure 4 shows where the gates are located with respect to the dumping point and register zone (RZ). The physical gates are marked in green, while the logical gates are illustrated in red.

It is important to mention that these gates can be relocated in the panels once a new drawpoint is added to the production program, i.e. they are not fixed. (JRI 2019d; Vega 2020).

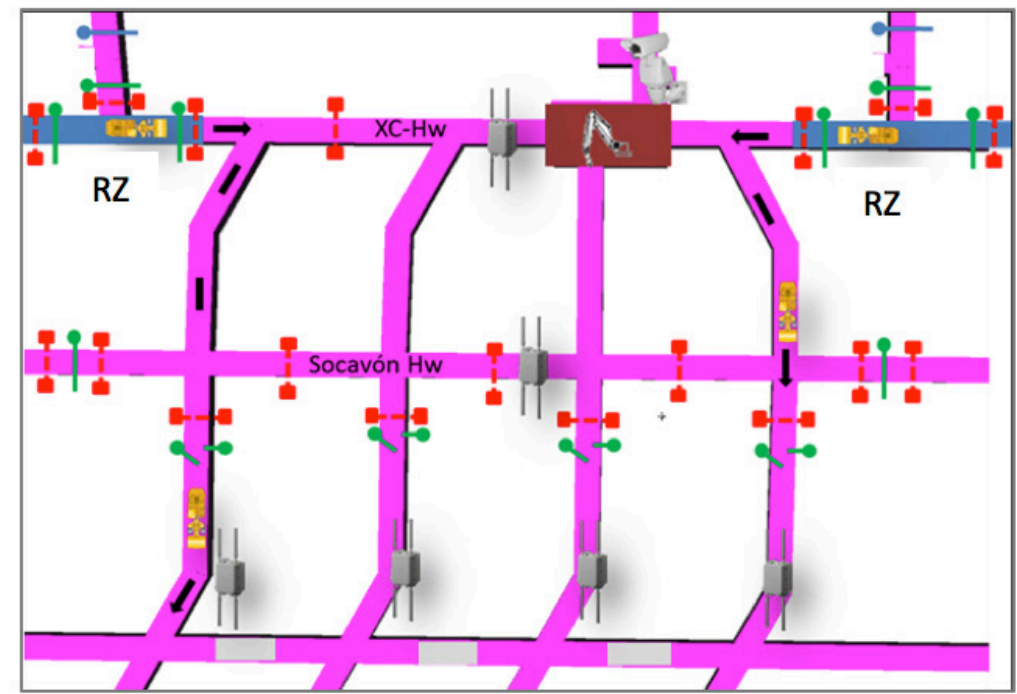

\section{Figure 4 Confinement-gate distribution}

- Register Zones (RZ)

The project considers a strategic location for the RZ (Figure 5). Register zones are close to the dumping point and will not interrupt LHDs in production activities. No loaders need to be stopped to add a new semi autonomous LHD to the production activity.

In addition, each RZ will be a local refuelling area for LHDs. Then, no operator is required to drive the LHD to the refuelling station and back to the production area. This activity will be done in situ in the footprint area (JRI 2019d; Vega 2020).

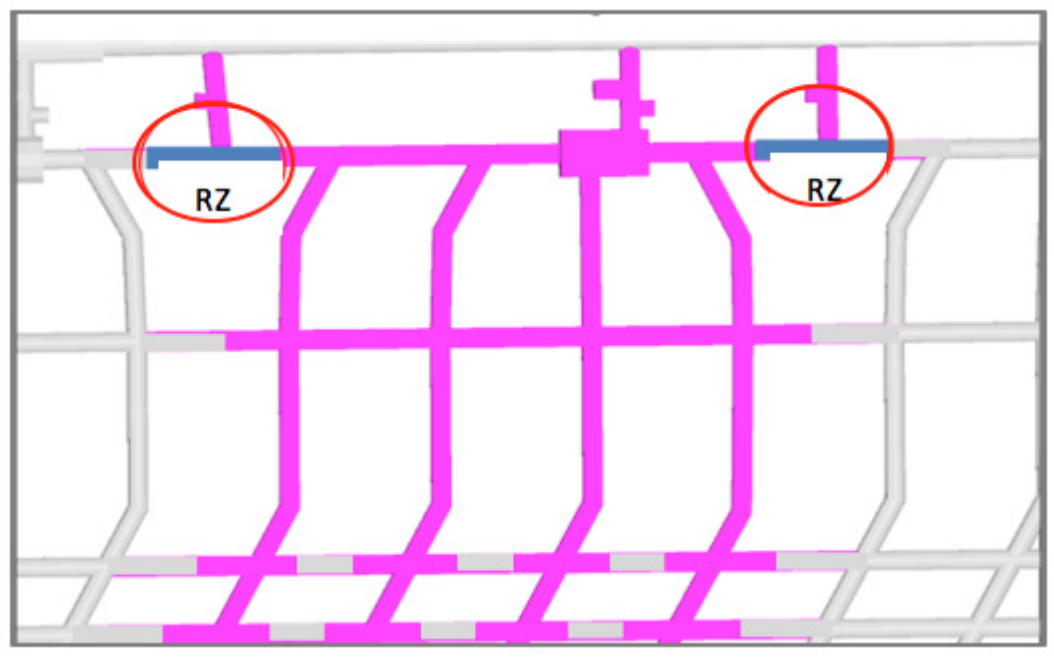

Figure 5 Register zone 


\section{$5.2 \quad$ Layout criteria}

The Extraction Level will have panels wide enough to make it easy for the semi autonomous production activity $(4.6 \times 4.5 \mathrm{~m}, \mathrm{~W} \times \mathrm{H}$, free area). These dimensions minimize any collision with the walls because of the LHD movements.

All LHD activities in terms of production will be completely automated and isolated in the footprint area. From refuelling to panel relocation, no operator on board is needed (JRI 2019b).

For maintenance purposes, an operator on board is needed to move the LHD from the RZ to the workshop area, and vice versa.

As this is a Panel Caving mine, the construction operators can access the Extraction Level through the RZ and will not interrupt the production activity as shown in Figure 6.

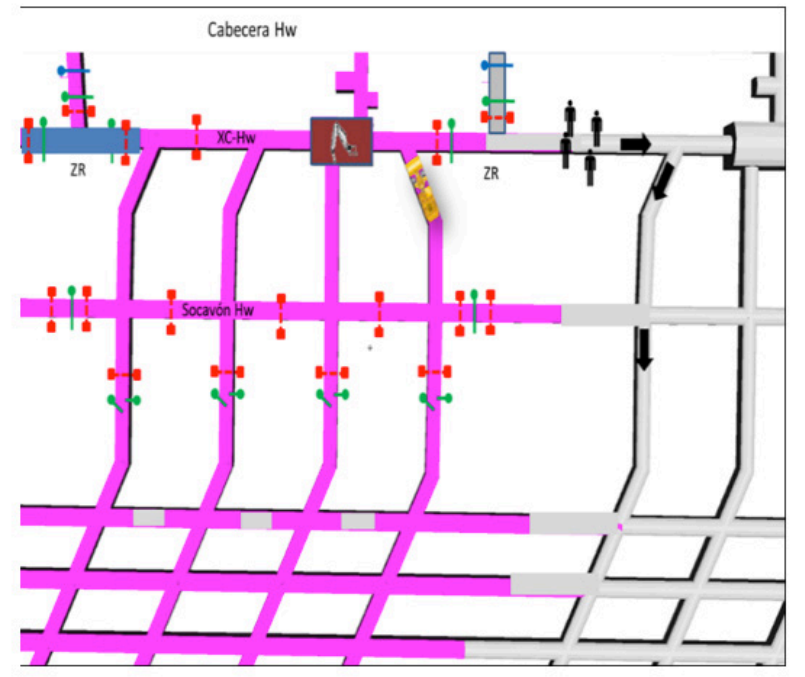

Figure 6 Access to the Extraction Level for construction activities

The design is friendly for different activities and allows for activities to coexist while taking into account safety restrictions and the company rules. In summary, the design considers the following criteria (Vega 2020):

- Suitable panel and dumping point dimensions.

- Well defined and safe confinement areas.

- Easy access for different activities.

- Strategic RZ location.

- Straightforward operational management (LHD relocation, secondary blasting, refueling, spillage cleaning, emergency cases).

\subsection{Andesita IPM}

The Extraction Level footprint layout will be divided into ten (10) different production areas as shown in Figure 7 and will have one dumping point for each production area, except for the area at the Southeast that has to dump to the West to avoid any bottle neck in the dumping point of the Southeast. At the same time, each panel will be divided into two (2): the East semi-panel and the West semi-panel (JRI 2019b). 
When taking the production sequence into account, the IPM for the Andesita Project will be defined depending on the philosophy described in Figure 2 and Table 1. For the dumping points located at the West, the recommendation is that at least the first two (2) drawpoints should be ready for production in each semi-panel, with a minimum safety distance of $100 \mathrm{~m}$ from construction activities in the same panel.

For the dumping points at the East, the recommendation is different. Because the construction activity goes towards the dumping point, the whole semi-panel should be already constructed and finished before semi autonomous activity begins (Vega 2020).
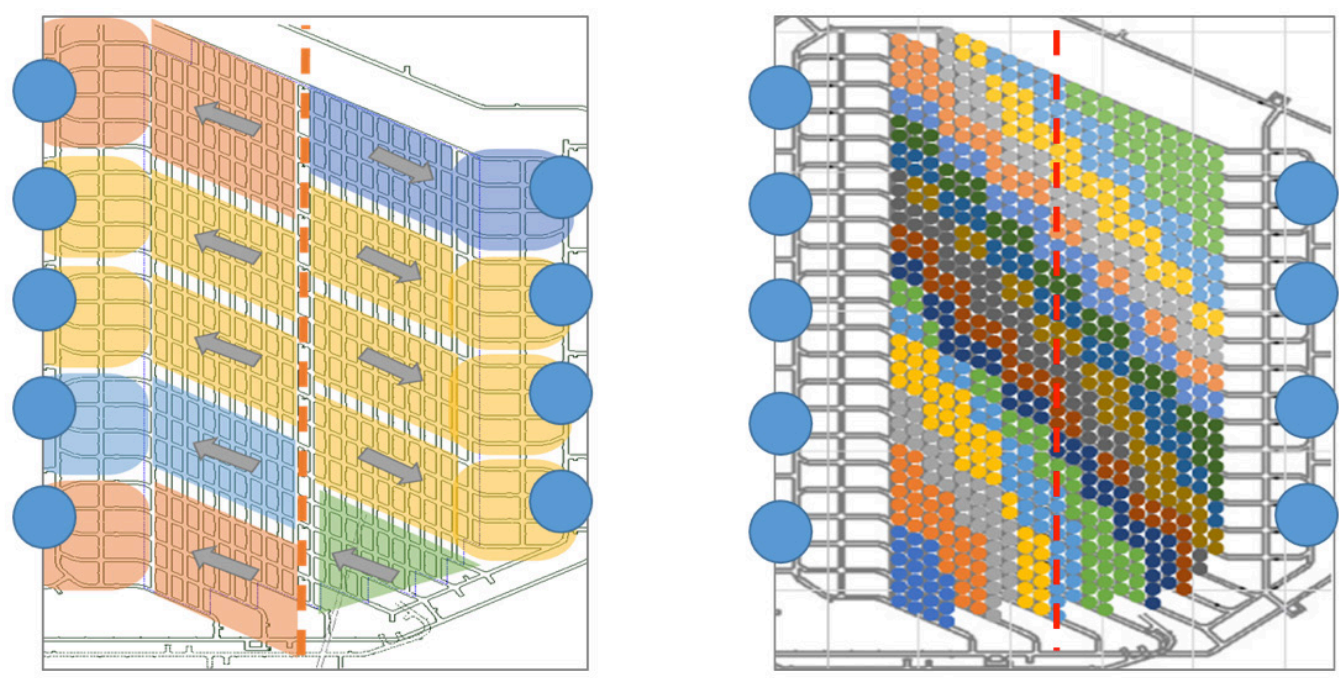

Figure 7 Extraction Level configuration, construction direction and production sequence

The strategy for the IPM and the dumping point is shown in Figure 8, and the basic idea is to isolate the area where the semi autonomous LHD will operate. In this case, the first panel (C-33) is the focus of the IPM. The whole access to the dumping point (dark gray color) is completely confined, and no other equipment can have access.

Other activities from other panels can continue with no interruption, even the mucking with an operator on board can dump into the same dumping point but from a different access. The layout design provides the opportunity to dump from another access and even to another dumping point if necessary (because of grizzly maintenance, for example) (Vega 2020; BCTEC 2019).

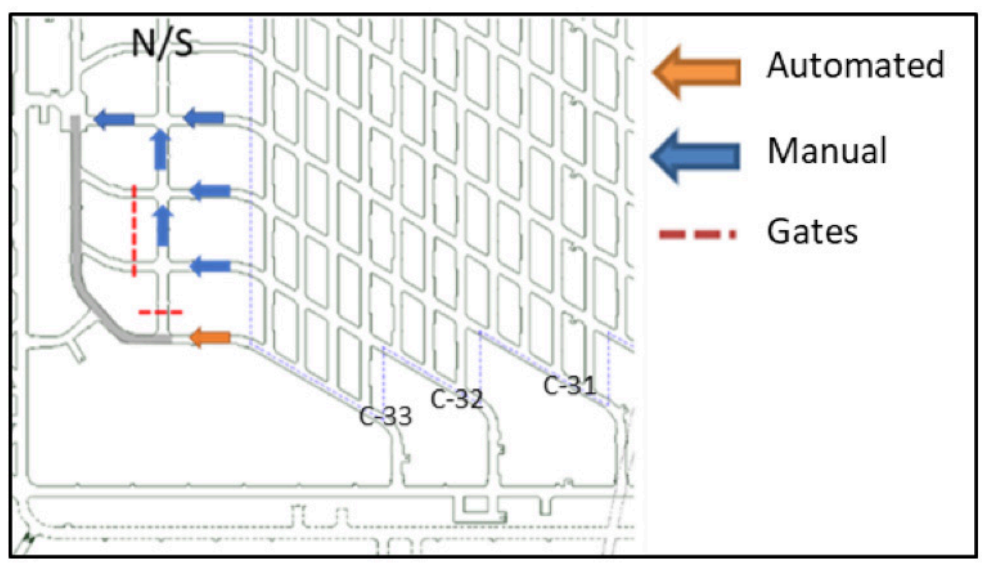

Figure 8 Strategy for the IPM 


\section{Conclusions}

An IPM should be defined as soon as possible for successful implementation of semi autonomous LHD usage in Panel Caving mines. Topics such as layout and technical criteria must be considered to facilitate this implementation, and though both can easily be implemented in most designs, there are three main concepts to reinforce:

- Preparing an IPM can expedite the initiation of semi autonomous production activity depending on the production sequence and the dumping point location.

- Design should be user-friendly for all production activities to minimize congestion and interruption.

- All isolated production areas where the semiautonomous LHDs operate must be fully constructed.

In the future, the challenges in panel caving mines will be focused on how to match this technology (semi autonomous LHD) with other processes such as undercutting or haulage levels activities. Fully autonomous mining is the goal.

\section{Acknowledgement}

The authors would like to thank CODELCO for their assistance with the development of this work and for providing the time and resources to complete this paper. Also, we would like to thank the BCTEC team for their support during the development of this study.

\section{References}

BCTEC, 2019, 'Initial Report Andesita Operational Analysis', Complementary studies for Andesita Project, in Spanish.

Codelco, 2018, 'Proyecto Explotación Andesita, División El Teniente', presentation, in Spanish.

Codelco, 2007, 'Post Evaluación Proceso de Extracción con LHD Semiautomático Sectores Pipa Norte \& Diablo Regimiento', internal report, in Spanish.

Gustafson, A 2013, 'Automation of Load Haul Dump Machines - Comparative Performance Analysis and Maintenance Modeling', PhD Thesis, University of Lulea, Lulea.

JRI, 2019a, 'Sistema Autónomo LHD', Andesita Project feasibility study, in Spanish.

JRI, 2019b, 'Informe Filosofía Operacional LHD', Andesita Project feasibility study, in Spanish.

JRI, 2019c, 'Análisis Operacional Andesita', Andesita Project feasibility study, in Spanish.

JRI, 2019d, 'Sistema Autónomo LHD Confinamiento y Zonas de Registro', Andesita Project feasibility study, in Spanish.

JRI, 2019e, 'Explotación Andesita Teniente', Andesita Project feasibility study, in Spanish.

JRI, 2018a, 'Simulación Capacidad Productiva Integral del Proyecto Andesita', Andesita Project feasibility study, in Spanish.

JRI, 2018b, 'Bases y Criterios de Diseño Automatización', Andesita Project feasibility study, in Spanish.

Riquelme, J. 2014, 'Fundamentos operacionales productivos y de automatización', MSc thesis, Universidad de Chile, Santiago, in Spanish.

Shekhar, G 2017, 'Loading Procedure and Draw Control in LKAB's Sublevel Caving Mines - Baseline Mapping Report', research report, University of Lulea, Lulea.

Uribe, P. 2014, 'Análisis de la funcionalidad y desempeño de la operación semi-autónoma en equipos de carga, acarreo y descarga en minería subterránea', MSc Thesis, Universidad de Chile, Santiago, in Spanish.

Vega, H. 2020, 'Metodología de automatización de LHD en minería del caving', MSc Thesis, Universidad de Chile, Santiago, in Spanish. 